\title{
The Therapeutic Management of Retroperitoneal Injuries
}

\author{
Crăciun C1', Azamfirei L², Coroș MF1, Hintea A¹, Cozma D1, Sorlea S1', Dobre A¹ \\ 1 Surgical Clinic 1, County Emergency Clinical Hospital, Tîrgu Mureș, Romania \\ 2 ICU Clinic 1, County Emergency Clinical Hospital, Tîrgu Mureș, Romania
}

\begin{abstract}
Background: In the retro peritoneum different organs of various origins (vascular, nervous, muscular, fascia, etc.) are located. These represent the source of different surgical conditions that cause, even today, serious problems of early diagnosis and treatment.

Material and method: We have conducted a retrospective study throughout a period of 8 years (2004-2011). We followed the incidence, the treatment and the evolution of several types of retroperitoneal lesions.

Results: In this period 79 cases of retroperitoneal conditions were encountered, representing $0.51 \%$ from the total of 15,284 patients admitted and treated within our clinic. The most common cases were those of tumour conditions and retroperitoneal primitive tumours (RPT). Many inflammatory conditions were also encountered. There were a few cases of retroperitoneal overflows or of parasitic diseases and we did not encounter cases of retroperitoneal fibrosis or malacoplaky.

Conclusions: In our study the majority of the retroperitoneal conditions were of tumour nature, especially malignant RPTs. Secondary retroperitoneal tumours (adenopathies, metastases, relapses) were less frequent. The excision of the retroperitoneal tumours is delicate, especially due to the vascular factor caused by anatomical conditions and their own vascularisation. On well-chosen cases we can use minimally invasive surgical techniques (laparoscope, punctures and eco-guided drainages), which enable a favorable post-operative evolution.
\end{abstract}

Keywords: retroperitoneal conditions, diagnosis, treatment

Received: 26 April 2012

\section{Introduction}

The retroperitoneal space is the anatomic-topographic region situated between the posterior peritoneal parietal layer and the osteo-muscular-aponeurotic level of the posterior abdominal wall. Its upper limit reaches the lumbar portion of the diaphragm (the $12^{\text {th }}$ rib and the $12^{\text {th }}$ thorax vertebra), sideways it extends up to the external edge of the square muscle of the lombs and the muscular-aponeurotic limit of the transversal abdominal wall, and the lower limit is at the level of the promontory and of the posterior portion of the uncalled lines (the upper strait of the pelvis) [1].

The retroperitoneal space within the anatomical limits described above can be considered as a posterior retroperitoneal space with more extensions: superior through the diaphragmatic holes or the Bourgery hiatus with the mediastinum and the inter-pleural space, anterior with the pro peritoneum, inferior from a retro groin point of view, pre-bladder (Retzius) and the pelvic-sub-peritoneal space, forming in this way the extra-peritoneal space $[1,2,3]$.

The retroperitoneal space is a very complex region, both from an anatomical point of view, through the multitude of organs and tissues from this level, and also through the pathology's variety. Even if lately there have been many progresses in diagnosing the retroperitoneal diseases, on numerous occasions they are discovered in their advanced stages, which complicates the treatment.

Correspondence to: Călin Crăciun

E-mail: c.craciun.calin@gmail.com

\section{Material and method}

We carried out a retrospective study at the Surgical Clinic 1 of the County Emergency Clinical Hospital of Tîrgu Mureș over a period of 8 years, between 2004 and 2011. We have followed the incidence, treatment and evolution of multiple types of retroperitoneal injuries: tumours, suppurative inflammatory conditions, retroperitoneal overflow, parasitic diseases, retroperitoneal fibrosis and malacoplaky.

In the study we took into account only the posterior retroperitoneum together with its caudal pelvic-sub-peritoneal extension, because from a clinical point of view many diseases originate from one place and develop into another one or vice-versa.

\section{Results}

In this period we had 79 cases of retroperitoneal conditions, representing $0.51 \%$ from the total of 15,284 patients admitted to the clinic (Table I). We can notice that the biggest share is given by tumour diseases and out of these, the most frequent were the retroperitoneal primitive tumours (RPT). Inflammatory conditions were also encountered. There were a few cases of retroperitoneal overflows or of parasitic diseases and we have not encountered cases of retroperitoneal fibrosis or malacoplaky.

In the studied interval, 43 patients $(54.43 \%$ from the total of the retroperitoneal diseases) have presented different forms of retroperitoneal primitive tumours, being more frequent in men ( 24 men vs. 19 women). The classification according to the evolving form is presented in Table II. 
Table I. The incidence of retro peritoneal injuries

\begin{tabular}{lc}
\hline Retroperitoneal injuries & Number of cases \\
\hline Tumours & 43 \\
Primitive & 30 \\
Malignant & 13 \\
Benign & 1 \\
Metastasis & 7 \\
Relapses & 17 \\
Inflammatory conditions & \\
Retroperitoneal overflow & 3 \\
Hemo retroperitoneum & 5 \\
Urohemo retroperitoneum & \\
Parasitic diseases & 3 \\
Hydatid cyst & 0 \\
Retroperitoneal fibrosis & 0 \\
Malacoplaky & \\
\hline
\end{tabular}

The distribution of tumours according to their pathological form, based on the origin of RPT, is presented in Table III. The distribution of benign or malignant evolutions is presented in Tables IV and V, respectively.

From the total of RPT patients only $12(27.9 \%)$ were admitted with the diagnosis of retroperitoneal tumour, and the average period of hospitalization of RPT patients was of 13.5 days (range 2-50 days), the average of post-operative days spent in the intensive care unit being 4.5 days, with a maximum of 35 days.

We encountered 7 retroperitoneal tumour relapses, which appeared after the operation intended to eradicate the tumour.

Retroperitoneal metastases, originating from malignant tumours situated elsewhere, are very rare. Most of the times, the presumed retroperitoneal metastases are actually invasions of nearby tumours or they might be invaded lymph nodes. In our study we have met a single case of retroperitoneal metastasis, an adeno-carcinoma of undetermined origin.

We encountered 17 cases of inflammatory lesions of the retroperitoneal space, 7 in women and 10 in men: 3 cases of perirenal abscesses fistulised in the recto-sigmoidian portion of the colon, with the histo-pathological result of a chronic inflammatory process, granulating with giant multinuclear cells (diverticulosis); 9 retroperitoneal abscesses without any other specification and a case of tumour mass which was removed, the histo-pathological result being abscess in the adipose tissue. Most of the cases were met in the 50-60 years age group.

Table III. The RPT grouping according to the tissue of origin

\begin{tabular}{lcc}
\hline According to the tissue of origin & & From the total RPT \\
\hline Tumours of mesoderm origin & 23 & $53.49 \%$ \\
Tumours of neurogenic origin & 4 & $9.30 \%$ \\
Tumours developed from embryonic & 2 & $4.65 \%$ \\
remnants & 8 & $18.60 \%$ \\
Different tumours & 6 & $13.95 \%$ \\
Cystic tumours & 43 & \\
Total & & \\
\hline
\end{tabular}

Table II. The anatomical pathological characters of RPT

\begin{tabular}{lcc}
\hline Evolution & & From the total RPT \\
\hline Benign tumours & 13 & $30.23 \%$ \\
Malignant tumours & 30 & $69.77 \%$ \\
Total & 43 & \\
Tumours with an indefinite histo- & 1 (considered & \\
pathological structure & benign) & \\
\hline
\end{tabular}

As far as retroperitoneal overflow and parasitic diseases are concerned, their incidence was quite small in our study, there were only 8 cases of retroperitoneal overflows, 3 hematic and 5 urohematic, and there were 3 hydatid cysts developed at this level. We have not encountered cases of retroperitoneal fibrosis or malacoplaky.

The incidence of retroperitoneal injuries depending on the age of the patients is shown in Table VI.

\section{Discussions}

The most frequent retroperitoneal injuries we have encountered were tumours, and out of these, primitive retroperitoneal tumours were the most frequent.

The clinical picture of retroperitoneal tumours is influenced by several factors, such as: the tissue of origin (nervous, vascular, lymphatic, adipose), the type of evolution (benign or malignant), but more important for the understanding of the symptoms is their location in the retroperitoneal space and the type of relation (compression, dislocation, invasion) which they have with the surrounding organs. The digestive disorders of high occlusion which manifest themselves especially through vomiting, are characteristic to the tumours located in the upper area of the retroperitoneal space, while tumours located inferiorly or pelvic-sub-peritoneal tumours mostly generate transit disorders characteristic to lower occlusions [4].

Pain is not pathognomonic for retroperitoneal tumours; usually it is caused by compressions or nervous invasions when its localisation, intensity and irradiation depend on the affected nerve torso. We have encountered cases with pain characteristic to renal colic, generated by compressions or by urethral invasion [5].

There have also been cases where due to the localisation in the lower region of the retroperitoneal space and to the

Table IV. The forms which presented a benign evolution

\begin{tabular}{lccc}
\hline Benign tumours & From the total & $\begin{array}{c}\text { From the RPT } \\
\text { of the benign } \\
\text { tumours }\end{array}$ & $\begin{array}{l}\text { total } \\
\text { Lipoma }\end{array}$ \\
Leiomyoma & 2 & $15.38 \%$ & $4.65 \%$ \\
Paraganglioma & 1 & $15.38 \%$ & $4.65 \%$ \\
Myxoma & 1 & $7.69 \%$ & $2.32 \%$ \\
Hemangioma & 1 & $7.69 \%$ & $2.32 \%$ \\
Cystic tumours & 6 & $7.69 \%$ & $2.32 \%$ \\
Total & 13 & $46.15 \%$ & $13.95 \%$ \\
\hline
\end{tabular}


Table V. The forms which presented a malignant evolution

\begin{tabular}{|c|c|c|c|}
\hline Malignant tumours & & $\begin{array}{c}\text { From the total } \\
\text { of the malignant } \\
\text { tumours }\end{array}$ & $\begin{array}{c}\text { From the RPT } \\
\text { total }\end{array}$ \\
\hline Liposarcoma & 6 & $20 \%$ & $13.95 \%$ \\
\hline Lymphomas & 7 & $23.33 \%$ & $16.28 \%$ \\
\hline Leiomyosarcoma & 4 & $13.33 \%$ & $9.30 \%$ \\
\hline Malignant Schwanoma & 4 & $13.33 \%$ & $9.30 \%$ \\
\hline Pheochromocytoma & 2 & $6.66 \%$ & $4.65 \%$ \\
\hline Seminoma & 2 & $6.66 \%$ & $4.65 \%$ \\
\hline $\begin{array}{l}\text { Malignant fibrous } \\
\text { histiocytoma }\end{array}$ & 1 & $3.33 \%$ & $2.32 \%$ \\
\hline $\begin{array}{l}\text { Undifferentiated } \\
\text { carcinoma }\end{array}$ & 3 & $10 \%$ & $6.98 \%$ \\
\hline $\begin{array}{l}\text { Solid papillary } \\
\text { neoplasm }\end{array}$ & 1 & $3.33 \%$ & $2.32 \%$ \\
\hline Total & 30 & & $69.77 \%$ \\
\hline
\end{tabular}

compression of the iliac veins, the unilateral edema of the lower limb was the only sign for which the investigations were continued, which led to the discovery of the retroperitoneal tumour.

We have not found a "syndrome" of the retroperitoneal tumours; their clinical picture is quite varied. This may explain the relatively small percentage of patients admitted directly with the diagnosis of retroperitoneal tumour.

The indications for surgical treatment in retroperitoneal conditions vary according to the nature of the tumour (primitive, relapsing, cystic, benign and malignant). All types of retroperitoneal tumours have a surgical indication, but the differences reside in their type and stage: with the intention of eradicating, palliative (cytoreductive, bioptical, for complications, marking), iterative, before or after an oncology treatment [2].

From the total RPT interventions with the intention to eradicate the tumour, this was possible in only 24 cases. Tumour extirpation was, in some cases, accompanied by other interventions: resections -5 segmental jejunal or ilea resections, 1 segmental transverse colon resection, 3 left hemicolectomy, 1 sigma segmental resection, 3 right hemilectomies; organ removal -4 splenectomies, 2 caudal
Table VI. The incidence of retroperitoneal tumours by age

\begin{tabular}{lccc}
\hline Age groups (years) & Number & Tumours & Other conditions \\
\hline $10-20$ & 3 & 1 & 2 \\
$20-30$ & 2 & 1 & 2 \\
$30-40$ & 6 & 4 & 4 \\
$40-50$ & 3 & 2 & 3 \\
$50-60$ & 15 & 12 & 11 \\
$60-70$ & 13 & 18 & 4 \\
$70-80$ & 10 & 12 & 2 \\
$>80$ & 1 & 1 & 0 \\
Total & 79 & 51 & 28 \\
\hline
\end{tabular}

spleen-pancreatectomies, 1 right nephrectomy, 3 cholecystectomies.

We came across two cases of retroperitoneal tumours of small sizes, well delimitated by the neighbouring organs, which at the CT scan with a contrast substance did not have dangerous connections with the large retroperitoneal blood vessels and which were completely removed through the laparoscope. The post-operative evolution of these patients was very good, they were discharged after 48 hours. The laparoscopic surgery of the retroperitoneal injuries is in an exploration stage. Singular cases are the ones which are mostly published, the experiences being under evaluation.

In 19 cases $(44.19 \%)$ total tumour removal was not possible due to vascular risk, and the following surgical procedures were performed: 5 exploratory laparatomies and 1biopsy; 4 cito-reductions; 2 simple laparatomies; 2 diagnostic laparatomies and 3 eco-guided puncture-biopsies.

Other palliative interventions were associated: 2 gastroentero-anastomosis and biopsy; 2 ileo-anastomosis transverso; 1 transverso-sigmoid-anastomosis.

Retroperitoneal relapses appear especially after malignant RPTs, because these tumours are dissected and removed in a cleavage plan, which is the result of compression onto the neighbouring organs. This plan is favourable for the surgical act, but most of the times it is not within oncologic limits. The 7 cases of retroperitoneal tumour relapses, which represent $29.16 \%$ from the total RPT op-
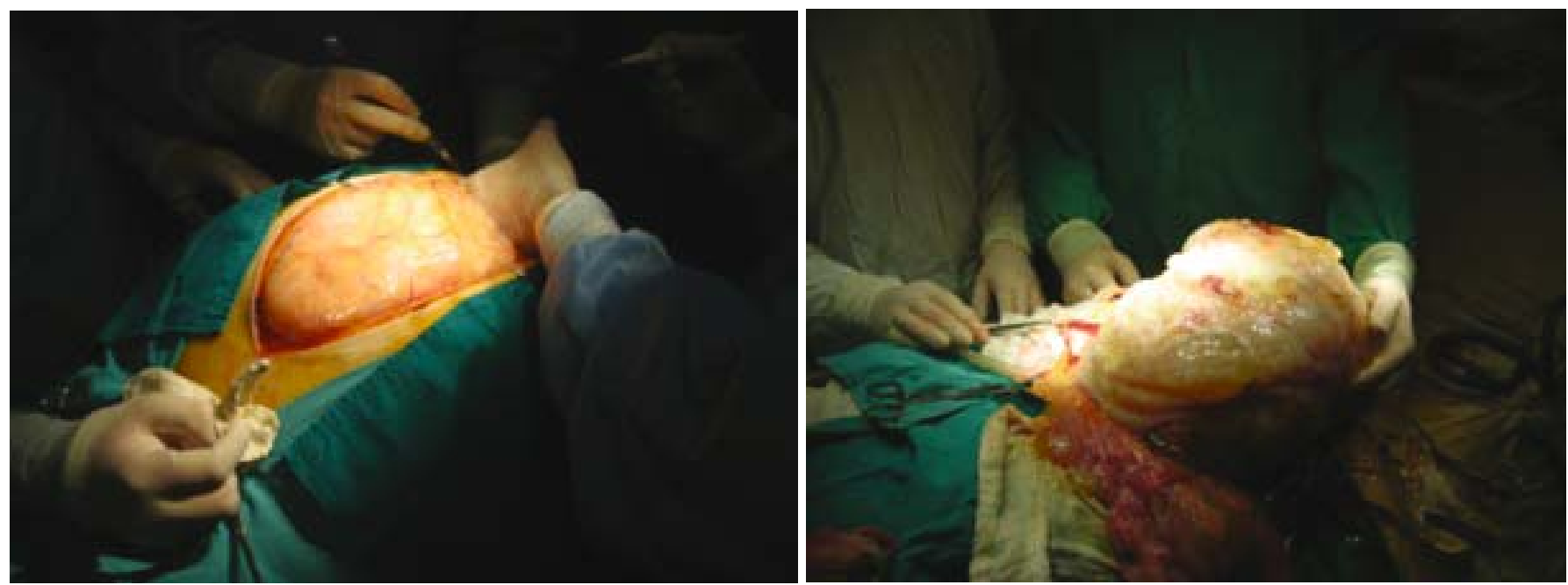

Fig. 1. Patient V.S., 56 years, retroperitoneal lipoma, intraoperative aspect 

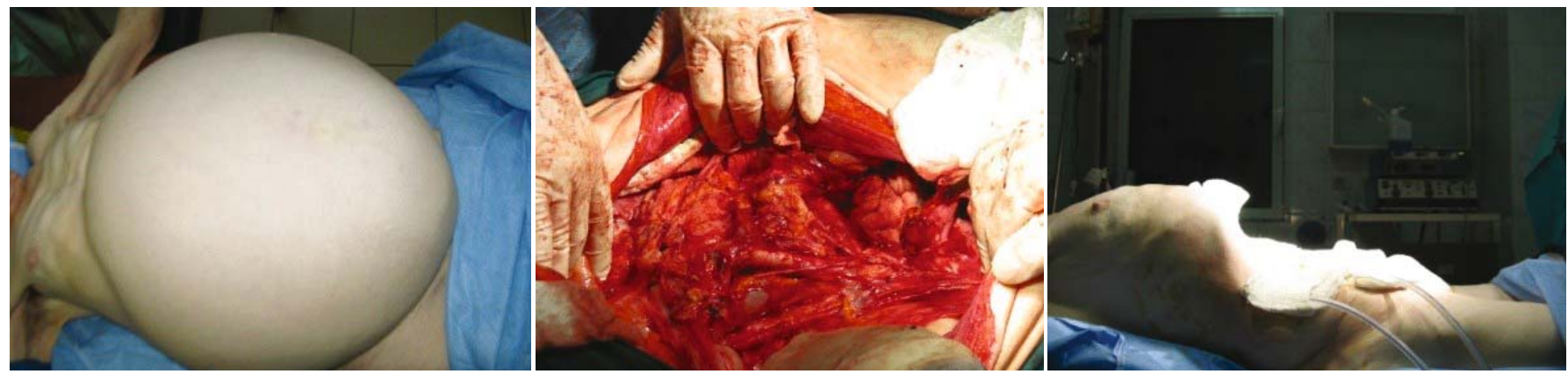

Fig. 2. Patient B.E., 72 years, retroperitoneal giant liposarcoma, before, during and after the operation

erated, appeared after 4 lipo sarcomas, 2 malignant lymphomas, a malignant schwannoma and they benefited of: 3 exploratory laparotomies and biopsy; 1 ileo-transverso anastomosis; 2 colostomies; for the retroperitoneal metastasis patient an exploratory laparatomy and biopsy were conducted (HP result: adeocarcinoma metastasis).

Inflammatory lesions are the second most frequent retroperitoneal conditions we have encountered. The symptoms of retroperitoneal suppurations are not characteristic, they are dominated by four important signs and symptoms: abdominal pain, muscular distress located especially in the hypogastrium and flanks, palpable tumour and low grade fever, each of them more or less developed from case to case; to these we add laboratory results (leukocytosis, increased VSH, positive PCR etc.) which can suggest the inflammatory nature of the lesion. The treatment for the retroperitoneal suppurations was medico-surgical, where alongside the surgical intervention which implies evection laparatomies of the suppurative content or of the necrotic tissues, anti-biotherapy and hydro-electrolytic rebalancing were used. There was a case where an eco-guided evection puncture was done, without the necessity of another surgical intervention.

Retroperitoneal overflows (hematic or combined)were more rarely met in our cases, as these appear especially as a result of a trauma of the retroperitoneal vessels, fractures or trauma inflicted to the retroperitoneal organs. Still, we have encountered 8 cases of retroperitoneal hematoma, which appeared after percutaneous nephrolithotomy (PCNL).

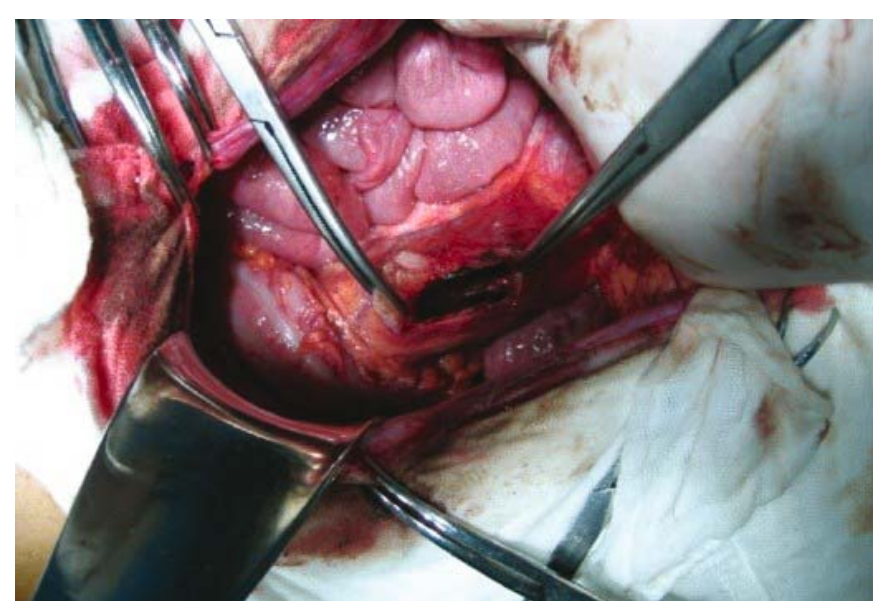

Fig. 3. Patient B.I., 43 years, hydatid cyst located in the retroperitoneal region
In 3 cases of retroperitoneal urohematoma, overflows appeared after PCNL procedures: evacuation, toileting and drainage which have been done through the laparoscope, with a good post-operative evolution. The hydatid cysts localised in the retroperitoneal area have been discovered due to other investigations, without showing anything characteristic for this localisation of the hydatiosis. In all the cases, surgical interventions to inactivate and evacuate have been done, followed by antiparasitic treatment.

\section{Conclusions}

In our study retroperitoneal lesions were rarely met in the surgical pathology $(0.51 \%)$, their incidence being higher after the $5^{\text {th }}$ decade of life, a period when the retroperitoneal tumours' frequency also increases, compared with the rest of the retroperitoneal conditions. The most frequent retroperitoneal lesions are of tumour origin, which are dominated by primitive retroperitoneal tumours (RPT). The anatomic relations of these tumours with the big retroperitoneal vessels make them surgically unapproachable. Nevertheless, obtaining a hysto-pathological result in the case of radically inoperable malignant tumours is important, as many of them are sensitive to either radio- or chemotherapy. In the case of the inflammatory and suppurative lesions that we encountered, the surgical treatment imposed itself to solve the infectious source, together with the anti-biotherapy and the hydro-electrolitycal rebalancing, and in the case of the retroperitoneal hematic overflows their volume and extension being big, they needed surgical interventions for the toileting and for the haemostasis.

\section{References}

1. Seres-Sturm L, Brînzaniuc Klara, Nicolescu C. Anatomia Trunchiului. University Press, Târgu-Mureș, 2004;230-263.

2. Popovici A. Patologia chirurgicală a spațiului retroperitoneal. În : Angelescu N, sub redacția. Tratat de Patologie Chirurgicală Vol II. București: Editura Medicală; 2001;1799-1824.

3. Testut $L$, Jacob O. Traité D'Anatomie Topographique avec Applications Médico-Chirurgicales- II. Doin et Fils, Paris, 1914.

4. Francis C. Nance. Diseases of the Peritoneum, Retroperitoneum, Mesentery, and Omentum in William S. Haubrich and Fenton Schaffne. Bockus Gastroenterology, $5^{\text {th }}$ Edition, Volume 4. W.B.Saunders Company, Philadelphia, USA, 1995;3081-3085.

5. Setlacec D, Proca E, Popa C. Tumorile retroperitoneale primitive. București: Editura Medicală 1986.

6. Vasile I, Vîlcea D, Nemes $R$, et al. Tumorile retroperitoneale primitive probleme de diagnostic si tratament. Chirurgia. 2005;100(1):27-33. 